\title{
Adverse Childhood Experiences and Spanking Have Similar Associations with Early Behavior Problems
}

\author{
Julie $\mathrm{Ma}, \mathrm{PhD}^{1}$, Shawna J. Lee, $\mathrm{PhD}^{2}$, and Andrew Grogan-Kaylor, $\mathrm{PhD}^{2}$
}

\begin{abstract}
Objectives To examine whether adverse childhood experiences (ACEs) and physical punishment (ie, spanking) are unique risk factors for behavior problems in early childhood, and whether ACEs moderate the associations of spanking with child behavior problems.

Study design We conducted prospective, longitudinal analyses on 2380 families in the Fragile Families and Child Wellbeing Study. Mothers reported outcomes of externalizing and internalizing behavior problems at age 5 years; and the main predictors, ACEs and spanking, at age 3 years. ACEs included 9 items: physical abuse, emotional abuse, physical neglect, emotional neglect, mother's exposure to intimate partner violence, parental mental health problem, parental substance use, parental incarceration, and parental death. Multilevel models examined the associations between ACEs, spanking, and behavior problems, and the moderating effect of ACEs in the associations of spanking with behavior problems. Analyses were adjusted for preexisting behavior problems, demographics, and neighborhood conditions.

Results ACEs $(\beta=0.028 ; P<.001)$ and spanking $(\beta=0.041 ; P<.001)$ at 3 years were unique risk factors for increased externalizing behavior problems at 5 years, after controlling for covariates. The magnitude of the associations of ACEs and spanking with externalizing behavior were statistically indistinguishable. ACEs did not moderate the association between spanking and externalizing behavior.

Conclusions ACEs and spanking have similar associations in predicting child externalizing behavior. Results support calls to consider physical punishment as a form of ACE. Our findings also underscore the importance of assessing exposure to ACEs and physical punishment among young children and providing appropriate intervention to children at risk. (J Pediatr 2021; $\mathbf{\square}: 1-8)$.
\end{abstract}

\section{See editorial, p •••}

dverse childhood experiences (ACEs) negatively affect physical and mental health outcomes. ${ }^{1,2}$ Exposure to ACEs in early childhood is a major public health concern. More than one-half of socioeconomically disadvantaged children living in 20 US cities experienced at least 1 ACE by age 5 years. ${ }^{3,4}$ ACEs comprising different forms of child maltreatment are common. In a study of 1007 urban children in the US, 16\% experienced emotional abuse, 13\% experienced neglect, and $15 \%$ experienced physical abuse at 5 years. ${ }^{4}$ Violence in the household is another common ACE, with $11 \%$ of 5 -year-olds living in households that reported intimate partner violence. ${ }^{4}$

Exposure to ACEs in early childhood has unique associations with increased levels of child externalizing and internalizing behavior problems. ${ }^{3,5,6}$ Another risk for increased child behavior problems is parental physical punishment, colloquially called spanking. In 2006, the United Nations Committee on the Rights of the Child indicated that any physical punishment is an act of physical assault that violates children's human rights. ${ }^{7}$ Professional organizations including the American Academy of Pediatrics and the American Psychological Association, also recommend against physical punishment on the basis of a robust literature demonstrating its association with a host of negative child outcomes. ${ }^{8-10}$ Physical punishment, including spanking, should be considered an ACE. ${ }^{11-13}$ Nonetheless, physical punishment in the US is legally allowable unless there is physical injury to child and most American parents differentiate spanking as a form of discipline that is not physical abuse. ${ }^{14}$ Reflecting this legal and cultural context, spanking remains a common experience for young children in the US (54\% at 3 years). ${ }^{15,16}$

Prior studies have not used longitudinal data from early childhood to prospectively examine whether ACEs and physical punishment play a similar role in the development of child behavior problems.

ACE

FFCWS

CTS-PC

$\mathrm{NSCH}$

SEEK
Adverse childhood experience

The Fragile Families and Child Wellbeing Study

Parent-Child Conflict Tactic Scales

National Survey of Children's Health

Safe Environment for Every Kid
From the ${ }^{1}$ Department of Social Work, University of Michigan-Flint, Flint; and the ${ }^{2}$ School of Social Work, University of Michigan, Ann Arbor, MI

The authors declare no conflicts of interest.

0022-3476/\$ - see front matter. @ 2021 Elsevier Inc. All rights reserved. https://doi.org/10.1016/.jpeds.2021.01.072 
One study demonstrated that physical punishment was associated with poorer adult mental health, even when accounting for exposure to ACEs in childhood. ${ }^{13}$ However, this study was conducted with adults, was retrospective in nature, and thus may be subject to recall bias.

The current study used longitudinal data to examine the unique effects of ACEs and maternal physical punishment on externalizing and internalizing behavior problems in early childhood (3-5 years of age), and the moderating role of ACEs in the associations of physical punishment with behavior problems. We controlled for key demographic factors associated with ACEs and physical punishment such as parent's age, race and ethnicity, education, poverty status, and marital status, and child age and sex. ${ }^{10,16} \mathrm{We}$ also accounted for neighborhood conditions because research demonstrates the associations of neighborhood disadvantage with family environment, parenting, and early child development. ${ }^{15}$ On the basis of the extant literature, we hypothesized that ACEs and physical punishment would be associated with increased levels of externalizing and internalizing behavior problems. Further, we hypothesized that ACEs would not moderate the associations between physical punishment and child behavior problems because prior evidence suggests that the associations of physical punishment with negative child outcomes are not moderated by parent, household, and contextual factors. ${ }^{17-21}$

\section{Methods}

The present analysis was based on children and their parents in the Fragile Families and Child Wellbeing Study (FFCWS). The FFCWS sampled children born between 1998 to 2000 in 20 US cities with a population of more than 200000 $(\mathrm{n}=4898)$. By study design, the FFCWS oversampled children born to mothers who were not married to their child's biological father to represent nearly three-quarters of the FFCWS sample. ${ }^{22}$ Mothers participated in the in-person baseline interviews in hospitals shortly after giving birth to the focal child (wave 1). Follow-up phone interviews were conducted when the focal child was age 1 years (wave 2), age 3 years (wave 3 ), age 5 years (wave 4 ), age 9 years (wave 5), and age 15 years (wave 6).

\section{Study Sample}

The study sample was limited to families who participated in the wave 3 interview during which ACEs and physical punishment were assessed and the wave 4 interview that assessed child behavior problems $(n=2488)$. We also excluded families without data on census tracts, the neighborhood proxy in this study, owing to incomplete address, nonresponse, and residence outside of the US. Our final analytic sample was 2380 families. In comparison with the full sample, mothers in the analytic sample had higher levels of education, were more likely to be married or cohabiting with the focal child's biological father, and lived in neighborhoods with higher levels of poverty at statistically significant levels. A greater proportion of mothers in the analytic sample reported their race as non-Hispanic Black, and a smaller proportion were Hispanic. Across all study variables, missing data were less than $1 \%$, except parent criminal justice system involvement, which was missing for $6.8 \%$ of the analytic sample. To account for possible biases introduced by missing data, we used a multiple imputation through chained equations procedure in STATA 15 (StataCorp LLC, College Station, Texas) to create 20 datasets. ${ }^{23}$ All study variables were included in imputation models. We report combined estimates from the 20 imputed datasets.

\section{Measures}

\section{Outcomes}

Child Behavior Problems. The outcomes were children's externalizing and internalizing behavior problem scores at wave 4 ( 5 years) that were reported by the mother (not true $=0$; somewhat or sometimes true $=1$; very true or often true $=2$ ) using the Child Behavior Checklist $/ 4-18 .^{24}$ Externalizing behavior at 5 years was the average of 20 items $(\alpha=0.85)$, which asked questions such as whether the child destroys his or her own things; is cruel, bullies, and shows meanness to others; or physically attacks people. Internalizing behavior at 5 years was the average of 22 items ( $\alpha=0.76$ ), which included questions such as whether the child is unhappy, sad, or depressed; feels or complains no one loves him or her; or is underactive, slow moving, or lacks energy.

\section{Main Predictors}

ACEs. At wave 3 (3 years), the mother reported whether each of the 9 binary ACEs categories had occurred in the past year (not occurred $=0$; occurred $=0$ ). Responses to the 9 ACEs categories defined below were summed to create a total ACEs score. ${ }^{1}$

The subscales of the Parent-Child Conflict Tactic Scales (CTS-PC) assessed whether maltreatment-physical abuse (4 items; hit with a hard object; shook; slapped; pinched), emotional abuse (5 items; swore or cursed; said you would send the child away or would kick the child out; shouted, yelled, or screamed; threatened to spank or hit; or called the child dumb or lazy), physical neglect (4 items; was not able to provide food that the child needed; left the child home alone; was not able to make sure the child got to a doctor or hospital when needed; was so drunk/high that you had a problem taking care of the child), and emotional neglect (1 item; was caught up with own problems and was not able to show love to the child)-occurred in the past year (never, once, twice, 3-5 times, 6-10 times, 11-20 times, $>20$ times). ${ }^{25}$ We excluded 1 item from the CTS-PC physical abuse subscale that measured spanking (ie, spanked the focal child on the bottom with bare hand) to differentiate spanking from physical abuse in the analyses. ${ }^{16}$ Following the CTS-PC scoring guidelines, the midpoint scores were assigned for each response category (never $=0$, once $=1$, twice $=2,3-5$ times $=4,6-10$ times $=8,11-20$ times $=15,>20$ times $=25) .{ }^{26}$ Consistent with past FFCWS ACEs literature, families were 
assigned a value of 1 (= occurred) on the maltreatment categories if they scored in the top 10th percentile on any of the 5 items for emotional abuse and on any of the 4 items for physical abuse and physical neglect, and on the emotional neglect item. ${ }^{3,4}$ Our scoring of maltreatment mirrors the CDC-Kaiser Permanente ACEs Study, which indicated parental maltreatment if it occurred frequently (ie, often or very often), except for any occurrence of being hit so hard that it resulted in an injury. ${ }^{1}$

Parental mental illness and substance use were assessed using the Composite International Diagnostic Interview-Short Form. ${ }^{27}$ Parental mental illness was coded as 1 if the mother or the biological father met the criteria for depression and/or anxiety. Parental substance use was coded as 1 if the mother or the biological father met the diagnostic criteria for alcohol or substance dependence.

The mother's exposure to intimate partner violence was measured by 3 items on physical abuse and sexual coercion derived from the Revised Conflict Tactics Scales (slaps or kicks; hits with a fist or an object; tried to make you have sex or do sexual things you didn't want to do) and 3 items on psychological aggression from the Spouse Observation Checklist (eg, keeps you from seeing or talking with your friends or family). ${ }^{28,29}$ Intimate partner violence was coded as 1 if the mother had been exposed to any type of intimate partner violence from the child's father or her current partner.

Parental criminal justice system involvement was assessed by the mother's report when the focal child was 3 years of age whether the mother had a pending charge against her and whether the child's father was in prison or jail. An affirmative response to either question was coded as 1.

Parental death was coded as 1 if the mother reported that the child's father was dead at the time of the 3-year interview. Maternal Spanking. Maternal spanking at age 3 years was measured by the following question: "Sometimes children behave pretty well and sometimes they don't. In the past month, have you spanked (child) because (he/she) was misbehaving or acting up?" (never $=0$, only once or twice in the past month $=1$, a few times this past month $=2$, a few times a week or more often $=3$ ). We created a dichotomous variable that was coded as 1 if the mother had spanked the child in the past month.

\section{Covariates}

Child Behavior Problems at 3 Years. Behavior problems at age 3 years were included in the analyses to control for preexisting behavior problems that might predict spanking and ACEs. Externalizing and internalizing behavior problem at 3 years were reported by mothers using the Child Behavior Checklist $/ 2-3 .^{30}$ Externalizing behavior problems at 3 years was the average of 15 items $(\alpha=0.86)$, which included items such as whether the child is defiant; gets in many fights; or hits others. Internalizing behavior problems at 3 years was the average of 24 items $(\alpha=0.81)$, which asked questions such as whether the child looks unhappy without good reason; is nervous, high strung, or tense; or seems unresponsive to affection.

Neighborhood Conditions. At wave 3, the mother's perceived neighborhood collective efficacy was measured using 10 items from the informal social control (eg, likelihood of neighbors intervening when a fight broke out in front of their house) and social cohesion and trust (eg, people in their neighborhood can be trusted) subscales $(\alpha=0.86)$ derived from the Project on Human Development in Chicago Neighborhoods. ${ }^{31}$ Census tract indicated the tract in which the mother resided at wave 3 . Neighborhood poverty indicated the percent of families below the federal poverty threshold in 1999 in the census tract in which the mother lived at wave 3, derived from the 2000 US Census.

Demographic Characteristics. Our analyses also controlled for demographic characteristics that may have confounding associations with ACEs, parenting, and child behavior problems. Child sex $($ male $=1$, female $=2)$, maternal age in years, maternal race/ethnicity (non-Hispanic White $=1$, non-Hispanic Black $=2$, Hispanic $=3$, other race/ ethnicity $=4$ ), and maternal education (less than high school $=1$, high school degree or General Educational Development $=2$, some college/technical school $=3$, college degree or higher $=4$ ) were assessed at baseline. Child age was the focal child's age in months at the wave 3 (3 years) interview. Mothers reported their relationship status with the focal child's father (married $=1$, cohabiting $=2$, not married or cohabiting $=3$ ) at wave 3 . Household poverty at wave 3 was the ratio of the mother's self-reported annual household income to the federal poverty threshold for the year preceding the interview $(\geq 200 \%=0,100-199 \%=1$, below poverty level $=2$ ). The US Census Bureau establishes the federal poverty level each year, which is a dollar amount that varies by family size and composition but does not differ geographically. ${ }^{32}$

\section{Statistical Analyses}

We used multilevel models with random intercepts to examine the associations between ACEs ( 3 years), maternal spanking (3 years), and externalizing and internalizing behavior problems (5 years) and the moderating effect of ACEs in the associations of spanking with child behavior problems. Multilevel models account for the potential clustering of individual responses within neighborhoods in the estimates. ${ }^{33}$ In the current study, responses to neighborhood conditions are likely to be correlated for families residing in the same neighborhood (ie, census tract). Thus, child- and parent-level variables were estimated as level 1 predictors in the models and a random intercept for the census tract was included at level 2 to control for the correlations of individual-level variables within the same census tract. To examine whether the associations of ACEs and spanking with child behavior problems were statistically different, we tested the equality of coefficients for ACEs and spanking after multiple imputation estimation. All analyses were conducted using Stata 15.1 (StataCorp LLC, College Station, Texas). ${ }^{34}$ 


\begin{tabular}{|c|c|c|c|c|c|c|}
\hline \multirow[b]{2}{*}{ Variables } & \multicolumn{3}{|c|}{ Full sample } & \multirow{2}{*}{$\begin{array}{c}\begin{array}{c}\text { Spanked } \\
\mathrm{n}=1288(55 \%)\end{array} \\
M(S D) \text { or } \%\end{array}$} & \multirow{2}{*}{$\begin{array}{c}\begin{array}{c}\text { Not spanked } \\
\mathrm{n}=1075(45 \%)\end{array} \\
M(S D) \text { or } \%\end{array}$} & \multirow[b]{2}{*}{$P$ value } \\
\hline & $\mathbf{n}$ & Missing & M (SD) or \% & & & \\
\hline \multicolumn{7}{|l|}{ ACES } \\
\hline Physical abuse & 2361 & $0.8 \%$ & $19.44 \%$ & $26.91 \%$ & $10.55 \%$ & $.000^{\star}$ \\
\hline Emotional abuse & 2361 & $0.8 \%$ & $12.96 \%$ & $16.85 \%$ & $8.38 \%$ & $.000^{\star}$ \\
\hline Physical neglect & 2357 & $1.0 \%$ & $6.53 \%$ & $8.13 \%$ & $4.52 \%$ & $.000^{*}$ \\
\hline Emotional neglect & 2358 & $0.9 \%$ & $7.21 \%$ & $8.67 \%$ & $5.40 \%$ & $.002^{\dagger}$ \\
\hline Parents' mental illness & 2379 & $0.0 \%$ & $30.47 \%$ & $33.70 \%$ & $26.54 \%$ & $.000^{*}$ \\
\hline Mother's exposure to intimate partner violence & 2372 & $0.3 \%$ & $11.72 \%$ & $13.51 \%$ & $9.68 \%$ & $.004^{\dagger}$ \\
\hline Parents' substance use & 2379 & $0.0 \%$ & $4.29 \%$ & $5.36 \%$ & $2.79 \%$ & $.002^{\dagger}$ \\
\hline Parents' criminal justice system involvement & 2218 & $6.8 \%$ & $8.03 \%$ & $8.14 \%$ & $7.70 \%$ & .704 \\
\hline Father's death & 2380 & $0.0 \%$ & $0.80 \%$ & $0.62 \%$ & $1.02 \%$ & .276 \\
\hline Total ACEs & & & $0.99(1.14)$ & $1.19(1.24)$ & $0.76(0.94)$ & $.000^{\star}$ \\
\hline 0 & & & $42.12 \%$ & $35.55 \%$ & $50.25 \%$ & $.000^{\star}$ \\
\hline 1 & & & $31.66 \%$ & $32.52 \%$ & $30.46 \%$ & .303 \\
\hline 2 & & & $16.40 \%$ & $18.32 \%$ & $13.91 \%$ & $.006^{\dagger}$ \\
\hline 3 & & & $5.85 \%$ & $7.39 \%$ & $4.06 \%$ & $.001^{\dagger}$ \\
\hline$\geq 4$ & & & $3.98 \%$ & $6.22 \%$ & $1.32 \%$ & $.000^{*}$ \\
\hline \multicolumn{7}{|l|}{ Child characteristics } \\
\hline Externalizing behavior, age 5 y & 2380 & $0.0 \%$ & $0.42(0.25)$ & $0.46(0.25)$ & $0.38(0.25)$ & $.000^{*}$ \\
\hline Internalizing behavior, age 5 y & 2380 & $0.0 \%$ & $0.25(0.20)$ & $0.26(0.19)$ & $0.24(0.21)$ & $.012^{\ddagger}$ \\
\hline Externalizing behavior, age 3 y & 2362 & $0.8 \%$ & $0.65(0.39)$ & $0.71(0.39)$ & $0.58(0.39)$ & $.000^{\star}$ \\
\hline Internalizing behavior, age 3 y & 2362 & $0.8 \%$ & $0.40(0.24)$ & $0.41(0.24)$ & $0.38(0.25)$ & $.026^{\ddagger}$ \\
\hline Child sex (male) & 2380 & $0.0 \%$ & $51.89 \%$ & $54.19 \%$ & $48.93 \%$ & $.011^{\ddagger}$ \\
\hline Child age (months) & 2380 & $0.0 \%$ & $35.25(2.20)$ & $35.21(2.10)$ & $35.27(2.29)$ & .521 \\
\hline \multicolumn{7}{|l|}{ Parent and family characteristics } \\
\hline Mother's age (years) & 2380 & $0.0 \%$ & $28.10(6.04)$ & $27.60(5.97)$ & $28.65(6.03)$ & $.000^{\star}$ \\
\hline Race/Ethnicity & 2372 & $0.3 \%$ & & & & \\
\hline White, non-Hispanic & & & $21.60 \%$ & $21.38 \%$ & $22.17 \%$ & .645 \\
\hline Black, non-Hispanic & & & $51.26 \%$ & $56.07 \%$ & $45.46 \%$ & $.000^{*}$ \\
\hline Hispanic & & & $23.82 \%$ & $19.60 \%$ & $29.28 \%$ & $.000^{*}$ \\
\hline Other & & & $2.98 \%$ & $2.95 \%$ & $3.09 \%$ & .852 \\
\hline Education & 2377 & $0.1 \%$ & & & & \\
\hline Less than high school & & & $32.73 \%$ & $31.13 \%$ & $34.42 \%$ & .090 \\
\hline High school degree or GED & & & $30.76 \%$ & $31.91 \%$ & $29.58 \%$ & .223 \\
\hline Some college/technical school & & & $25.76 \%$ & $27.16 \%$ & $24.19 \%$ & .100 \\
\hline College degree or higher & & & $10.63 \%$ & $9.81 \%$ & $11.81 \%$ & .116 \\
\hline Mother's relationship to child's father & 2376 & $0.2 \%$ & & & & \\
\hline Married & & & $30.26 \%$ & $29.47 \%$ & $31.66 \%$ & .251 \\
\hline Cohabiting & & & $20.29 \%$ & $19.91 \%$ & $20.76 \%$ & .606 \\
\hline Not married or cohabiting & & & $49.45 \%$ & $50.62 \%$ & $47.58 \%$ & .141 \\
\hline Poverty status & 2380 & $0.0 \%$ & & & & \\
\hline$\geq 200 \%$ poverty level & & & $31.51 \%$ & $32.53 \%$ & $30.60 \%$ & .316 \\
\hline $100-199 \%$ poverty level & & & $25.25 \%$ & $25.47 \%$ & $24.93 \%$ & .765 \\
\hline$<100 \%$ poverty level & & & $43.24 \%$ & $42.00 \%$ & $44.47 \%$ & .229 \\
\hline \multicolumn{7}{|l|}{ Neighborhood characteristics } \\
\hline Neighborhood collective efficacy & 2349 & $1.3 \%$ & $3.55(0.94)$ & $3.49(0.94)$ & $3.60(0.94)$ & $.005^{\dagger}$ \\
\hline Neighborhood poverty & 2380 & $0.0 \%$ & $0.18(0.14)$ & $0.18(0.14)$ & $0.19(0.15)$ & .850 \\
\hline
\end{tabular}

GED, General Educational Development.

All variables measured at child age 3 y unless noted otherwise. The $\chi^{2}$ tests were conducted for binary and categorical variables. One-way ANOVAs were conducted for continuous variables.

${ }^{\star} P<.001$.

$\dagger P<.01$.

$\ddagger P<.05$.

\section{Results}

Table I presents descriptive characteristics of the study sample. At 3 years, $58 \%$ of the sample experienced 1 or more ACEs (range, $0-6$ ) and 55\% of children in the sample were spanked by their mother in the past month. The most prevalent ACEs reported in this sample were parents' mental illness (30.47\%) and physical abuse (19.44\%). Bivariate analyses demonstrated that the total number of ACEs was significantly higher among children who were spanked compared with total ACEs of children who were not spanked. Likewise, mothers who spanked their child reported higher levels of externalizing and internalizing behavior problems at 3 years and 5 years than their counterparts who did not spank. Statistical differences by maternal spanking were also found in child sex, maternal age, race/ethnicity, and neighborhood conditions. A greater percentage of children who were spanked in the past month at age 3 years were boys (54\%). Mothers who spanked were younger; more likely to report their race as Black, non-Hispanic; and reported lower levels of neighborhood collective efficacy than mothers who did not 
Table II. Bivariate correlations of maternal spanking and ACEs

\begin{tabular}{|c|c|c|c|c|c|c|c|c|c|c|c|}
\hline Characteristics & 1 & 2 & 3 & 4 & 5 & 6 & 7 & 8 & 9 & 10 & 11 \\
\hline 1. Maternal spanking & - & & & & & & & & & & \\
\hline 2. Total ACEs score & $0.184^{*}$ & - & & & & & & & & & \\
\hline 3. Physical abuse & $0.206^{*}$ & $0.528^{*}$ & - & & & & & & & & \\
\hline 4. Emotional abuse & $0.125^{\star}$ & $0.528^{\star}$ & $0.270^{*}$ & - & & & & & & & \\
\hline 5. Physical neglect & $0.064^{*}$ & $0.430^{*}$ & $0.120^{*}$ & $0.166^{\star}$ & - & & & & & & \\
\hline 6. Emotional neglect & $0.073^{*}$ & $0.436^{*}$ & $0.091^{*}$ & $0.118^{*}$ & $0.300^{\star}$ & - & & & & & \\
\hline 7. Parent's mental illness & $0.078^{*}$ & $0.565^{\star}$ & $0.079^{*}$ & $0.084^{*}$ & $0.075^{\star}$ & $0.082^{\star}$ & - & & & & \\
\hline $\begin{array}{l}\text { 8. Mother's exposure to intimate } \\
\text { partner violence }\end{array}$ & $0.059^{*}$ & $0.406^{\star}$ & $0.028^{*}$ & $0.100^{\star}$ & $0.087^{\star}$ & $0.085^{\star}$ & $0.070^{*}$ & - & & & \\
\hline 9. Parent's substance use & $0.064^{*}$ & $0.278^{\star}$ & 0.038 & $0.042^{*}$ & 0.030 & 0.037 & $0.166^{\star}$ & 0.021 & - & & \\
\hline $\begin{array}{l}\text { 10. Parent's criminal justice } \\
\text { system involvement }\end{array}$ & 0.008 & $0.327^{\star}$ & 0.046 & $0.047^{\star}$ & -0.007 & $0.080^{\star}$ & $0.113^{\star}$ & -0.003 & 0.016 & - & \\
\hline 11. Father's death & -0.022 & $0.044^{\star}$ & -0.008 & -0.007 & -0.025 & -0.005 & $0.043^{\star}$ & -0.018 & -0.019 & -0.011 & - \\
\hline
\end{tabular}

All variables measured at child age $3 \mathrm{y}$.

${ }^{\star} P<.05$ (or lower).

spank. Table II presents the correlations between spanking and ACEs. Spanking showed weak correlations with each ACEs category including physical abuse $(r=.206$; $P<.001)$, indicating that multicollinearity is not a concern in the analyses. ${ }^{35}$

Results from multilevel models are presented in Table III. ACEs at 3 years were associated with increased externalizing behavior $(\beta=0.028 ; P<.001)$ and internalizing behavior problems $(\beta=0.019 ; P<.001)$ at 5 years, after controlling for behavior problems at age 3 years, maternal spanking, neighborhood conditions, and demographic factors. Maternal spanking at 3 years predicted increased externalizing behavior problems at 5 years $(\beta=0.041$; $P<.001$ ), which was an increase in externalizing behavior by $0.164 \mathrm{SD}$ units. However, maternal spanking did not have a significant association with internalizing behavior problems after accounting for ACEs and other covariates. The nonsignificant intercepts for neighborhood variance in both models indicate that average levels of behavior problems did not differ across neighborhoods. ACEs were not a significant moderator of the associations between maternal spanking and externalizing behavior. Equality of coefficients for ACEs and spanking were not statistically different from each other in the relation to externalizing behavior $(F=1.59$; $P=.207)$.

\section{Discussion}

The current results support a growing call to expand the definition of ACEs to include spanking, because the experiences of physical punishment and ACEs are associated with similar negative outcomes in early childhood. ${ }^{11,36}$ Moreover, the negative child outcomes associated with ACEs and physical punishment can persist into adulthood. ${ }^{12,13}$ In the US, the legal definition of physical abuse does not include physical punishment unless a mark is left on the child. Despite this legal distinction between physical abuse and so-called nonabusive physical punishment, our findings demonstrate that the associations of ACEs and spanking with children's externalizing behavior problems are statistically indistinguishable, and that ACEs and maternal spanking at 3 years are unique risk factors for increased externalizing behavior problems at 5 years, net of preexisting behavior problems and demographic and neighborhood conditions.

As hypothesized, ACEs did not moderate the link between spanking and externalizing behavior, indicating that spanking worsens externalizing behavior regardless of exposure to other adversities. This pattern of results in which spanking is associated with early externalizing behavior problems is consistent with study hypotheses and social learning theory in which the use of physical punishment is thought to model the use of aggression to solve conflicts. ${ }^{37}$ It is also consistent with family coercive process theory in which physically coercive parenting is likely to escalate and contribute to children's likelihood of acting out (ie, externalizing behavior problems) and oppositional behavior patterns. ${ }^{38,39}$ Overall, the results of this study may be interpreted to suggest that the associations of physical punishment with child outcomes are statistically indistinguishable from the association of forms of maltreatment that are legally prohibited in the US context with the same child outcomes. This statistical indistinguishability may be because the underlying behaviorhitting children-has the same damaging effect on children, despite the presence of legal guidelines that attempt to differentiate between physical punishment and child maltreatment. $^{40}$

Also consistent with study hypotheses, ACEs were associated with internalizing behavior problems; however, somewhat in contrast with attachment theory and with our expectations, spanking was not associated with internalizing behavior after controlling for exposure to ACEs. ${ }^{41}$ Notably, prior FFCWS studies that examined the link between spanking and internalizing behavior demonstrate similar mixed findings. ${ }^{15,42}$ The null finding on internalizing symptoms in our study may be due to the less prevalent manifestation and consequent lower ability to detect internalizing symptoms in early childhood, noting that behavior problems in this study were measured when children were age 5 years. ${ }^{43}$ It is also possible that ACEs such as physical abuse, neglect, and exposure to 
Table III. Multilevel models for the associations

between ACEs (age $3 \mathrm{y}$ ), maternal spanking (age $3 \mathrm{y}$ ), and behavior problems (age $5 \mathrm{y}$ ) and the moderating effect of ACEs in the associations of maternal spanking with behavior problems adjusted for preexisting behavior problems, demographics, and neighborhood conditions

\begin{tabular}{|c|c|c|}
\hline Characteristics & $\begin{array}{l}\text { Externalizing } \\
\text { Behavior }\end{array}$ & $\begin{array}{l}\text { Internalizing } \\
\text { Behavior }\end{array}$ \\
\hline \multicolumn{3}{|l|}{ Fixed effects } \\
\hline ACES & $\begin{array}{l}0.028^{\star} \\
(0.007)\end{array}$ & $\begin{array}{r}0.019^{*} \\
(0.006)\end{array}$ \\
\hline Maternal spanking & $\begin{array}{l}0.041^{*} \\
(0.012)\end{array}$ & $\begin{array}{c}0.013 \\
(0.010)\end{array}$ \\
\hline ACEs $\times$ maternal spanking & $\begin{array}{r}-0.013 \\
(0.009)\end{array}$ & $\begin{array}{r}-0.002 \\
(0.007)\end{array}$ \\
\hline Behavior problem at age $3 \mathrm{y}$ & $\begin{array}{r}0.309^{*} \\
(0.012)\end{array}$ & $\begin{array}{l}0.333^{*} \\
(0.016)\end{array}$ \\
\hline Child sex & $\begin{array}{r}-0.021^{\ddagger} \\
(0.009)\end{array}$ & $\begin{array}{c}-0.008 \\
(0.007)\end{array}$ \\
\hline Child age & $\begin{array}{r}-0.002 \\
(0.002)\end{array}$ & $\begin{array}{c}0.000 \\
(0.002)\end{array}$ \\
\hline Mother's age & $\begin{array}{c}-0.001 \\
(0.001)\end{array}$ & $\begin{array}{c}-0.000 \\
(0.001)\end{array}$ \\
\hline \multicolumn{3}{|l|}{$\begin{array}{l}\text { Mother's race/ethnicity: White, } \\
\text { non-Hispanic }\end{array}$} \\
\hline Black, non-Hispanic & $\begin{array}{r}-0.043^{\star} \\
(0.013)\end{array}$ & $\begin{array}{r}-0.023^{\ddagger} \\
(0.011)\end{array}$ \\
\hline Hispanic & $\begin{array}{r}-0.035^{\ddagger} \\
(0.014)\end{array}$ & $\begin{array}{r}0.036^{\dagger} \\
(0.012)\end{array}$ \\
\hline 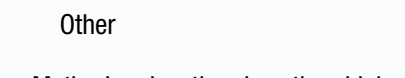 & $\begin{array}{c}-0.021 \\
(0.027)\end{array}$ & $\begin{array}{c}0.012 \\
(0.022)\end{array}$ \\
\hline \multicolumn{3}{|c|}{ Mother's education: less than high school } \\
\hline High school degree or GED & $\begin{array}{r}-0.008 \\
(0.011)\end{array}$ & $\begin{array}{c}0.005 \\
(0.009)\end{array}$ \\
\hline Some college/technical school & $\begin{array}{r}-0.014 \\
(0.013)\end{array}$ & $\begin{array}{r}-0.010 \\
(0.011)\end{array}$ \\
\hline College degree or higher & $\begin{array}{c}-0.033 \\
(0.020)\end{array}$ & $\begin{array}{l}0.010 \\
(0.017)\end{array}$ \\
\hline \multicolumn{3}{|l|}{ Mother's relationship status: married } \\
\hline Cohabiting & $\begin{array}{c}0.009 \\
(0.013)\end{array}$ & $\begin{array}{c}0.018 \\
(0.011)\end{array}$ \\
\hline Not married or cohabiting & $\begin{array}{l}0.042^{*} \\
(0.012)\end{array}$ & $\begin{array}{c}0.006 \\
(0.010)\end{array}$ \\
\hline \multicolumn{3}{|l|}{ Poverty status: $\geq 200 \%$ poverty level } \\
\hline $100 \%-199 \%$ poverty level & $\begin{array}{c}0.023 \\
(0.013)\end{array}$ & $\begin{array}{c}0.006 \\
(0.011)\end{array}$ \\
\hline$<100 \%$ poverty level & $\begin{array}{l}0.014 \\
(0.013)\end{array}$ & $\begin{array}{c}0.013 \\
(0.011)\end{array}$ \\
\hline Neighborhood collective efficacy & $\begin{array}{r}-0.013^{\ddagger} \\
(0.005)\end{array}$ & $\begin{array}{l}-0.007 \\
(0.004)\end{array}$ \\
\hline Neighborhood poverty & $\begin{array}{l}0.040 \\
(0.035)\end{array}$ & $\begin{array}{c}0.031 \\
(0.030)\end{array}$ \\
\hline Constant & $\begin{array}{l}0.357^{*} \\
(0.079)\end{array}$ & $\begin{array}{l}0.110 \\
(0.066)\end{array}$ \\
\hline \multicolumn{3}{|l|}{ Random effects } \\
\hline Intercept for neighborhood variance & $\begin{array}{l}0.000 \\
(0.000)\end{array}$ & $\begin{array}{c}0.000 \\
(0.000)\end{array}$ \\
\hline Residual variance & $\begin{array}{l}0.175 \\
(0.003)\end{array}$ & $\begin{array}{c}0.208 \\
(0.003)\end{array}$ \\
\hline
\end{tabular}

GED, General Educational Development.

Standard errors in parentheses.

${ }^{*} P<.001$.

$\dagger P<.01$.

$\ddagger P<.05$.

intimate partner violence may be stronger predictors of young children's internalizing behavior when compared with physical punishment.
More than one-half of the children in the current study were spanked at 3 years, and more than one-half had experienced 1 or more ACEs when they were age 3 years, with parental depression, physical abuse, and other forms of maltreatment, as well as exposure to violence toward the mother, being very common ACEs. ${ }^{3,4}$ The 2016 National Survey of Children's Health (NSCH) established that $35 \%$ of children aged 0-5 years had been exposed to at least 1 ACE. ${ }^{44}$ The rate of ACEs in the current study was higher. At 3 years of age, $58 \%$ of the sample experienced 1 or more ACEs. However, the NSCH measure of ACEs did not include the child's exposure to parental physical abuse, emotional abuse, or neglect. Also, the NSCH is a nationally representative sample of children from the 50 US states, whereas the FFCWS oversampled children born to unmarried mothers in 20 large US cities, resulting in an overrepresentation of socioeconomically disadvantaged families. Thus, experiences of ACEs may be higher among urban children born to unmarried parents.

Research demonstrates that the physical punishment including spanking that young children are commonly exposed to can escalate into more severe physical abuse that warrants intervention by the child welfare system. ${ }^{10,45,46}$ Our findings provide additional empirical evidence to support the American Academy of Pediatrics statement on physical punishment, which states that pediatricians provide counsel to parents to avoid physical punishment. ${ }^{8}$ The American Psychological Association issued a statement similarly calling for all parents to avoid the use of physical punishment. ${ }^{9}$ Practitioners may direct parents to the American Academy of Pediatrics patient education handout and the American Academy of Pediatrics online resource www.healthychildren.org on safe, appropriate alternatives to physical punishment, including verbal reasoning, redirecting the child, and selectively ignoring certain kinds of misbehavior. ${ }^{47,48}$

Experts have expressed concern that broadly screening for common ACEs, such as parental mental health issues, may lead to "unnecessary or intrusive intervention response." 4 However, in pediatric health care settings, interventions such as the Safe Environment for Every Kid (SEEK), have effectively used screening of parenting risk factors, that included questions about physical punishment, to advise parents against its use and offer parenting resources and support. Results from a randomized control trial of SEEK demonstrated that screening and intervention with parents may help to decrease the use of physical punishment, even among low-risk parents. ${ }^{50,51}$ The SEEK studies suggest that limited screening, particularly of prevalent risk factors (eg, physical punishment, maternal depression, and substance use) may facilitate health care professionals' ability to detect and ultimately prevent severe levels of parental maltreatment. ${ }^{50,51}$

Moving beyond a focus on parents, legislative reforms are warranted in countries in which physical punishment is legally allowable in order to shift social norms and behavior toward recognition that physical punishment is a violation of children's rights. As of 2020, 60 countries outlawed physical punishment and 28 countries have publicly committed to 
prohibit physical punishment as mandated by the United $\mathrm{Na}$ tions Convention on the Rights of the Child. ${ }^{52}$ Despite this global movement, the US is the only UN member state that has not ratified the United Nations Convention on the Rights of the Child. The US Centers for Disease Control and Prevention issued a technical package that highlights the need to decrease physical punishment through legislative approaches. ${ }^{53,54}$ This effort may include bans on any form of physical punishment, including spanking, as researchers have called for a shift in conceptualization of any hitting of children as abusive behavior and argued that based on the empirical evidence, "spanking be included as an adverse experience." ${ }^{11-13,40}$

The present study is not without limitations. Because the FFCWS oversampled children born to unmarried mothers in urban areas, the study sample is not representative of all families living in the US. Patterns of exposure to ACEs are likely to differ depending on sociodemographic characteristics. In the current study, mothers self-reported both ACEs and spanking; thus, increasing the potential for self-report biases. Given that most 3-year-olds would not yet be in school, mothers would be among the most reliable reporters of a young child's home environment, ACEs, and physical punishment. However, our findings are not free from potential under-reporting or over-reporting, which warrants the need for future research to obtain objective measurements in professional settings such as pediatric clinics. This study did not examine fathers' physical punishment and likely underestimated children's exposure to physical punishment from other caregivers. However, a prior FFCWS study showed that mothers' physical punishment only—but not fathers' physical punishment - was associated with subsequent child behavior problems. ${ }^{55}$ Another limitation is the possible underestimation of maltreatment, which used a high threshold to indicate abuse and neglect using the top 10th percentile in any CTS-PC items. One avenue for future research would be to examine the unique influence of each individual ACE and physical punishment on young children's development.

In conclusion, the results of this study are consistent with prior studies demonstrating the associations of physical punishment with negative child outcomes to be independent of other household, family and community conditions, including neighborhood environment, household income level, country of origin, race and ethnicity, cultural normativeness, and parent-child relationship quality. ${ }^{17-21,56,57}$ Our findings demonstrate that both ACEs and maternal physical punishment at 3 years are unique risk factors for increased child externalizing problems at 5 years, net of preexisting behavior problems and demographic and neighborhood conditions.

Submitted for publication Oct 19, 2020; last revision received Dec 30, 2020; accepted Jan 29, 2021.

Reprint requests: Julie Ma, PhD, Department of Social Work, University of Michigan-Flint, 303 East Kearsley Street, 454 French Hall, Flint, MI 48502. E-mail: majul@umich.edu

\section{References}

1. Felitti VJ, Anda RF, Nordenberg D, Williamson DF, Spitz AM, Edwards V, et al. Relationship of childhood abuse and household dysfunction to many of the leading causes of death in adults. The Adverse Childhood Experiences (ACE) Study. Am J Prev Med 1998;14:245-58.

2. Dube SR, Felitti VJ, Dong M, Chapman DP, Giles WH, Anda RF. Childhood abuse, neglect, and household dysfunction and the risk of illicit drug use: the adverse childhood experiences study. Pediatrics 2003;111:564-72.

3. Hunt TKA, Slack KS, Berger LM. Adverse childhood experiences and behavioral problems in middle childhood. Child Abuse Negl 2017;67: 391-402.

4. Jimenez ME, Wade R, Lin Y, Morrow LM, Reichman NE. Adverse experiences in early childhood and kindergarten outcomes. Pediatrics 2016;137:e20151839.

5. Suh B, Luthar SS. Parental aggravation may tell more about a child's mental/behavioral health than Adverse Childhood Experiences: Using the 2016 National Survey of Children's Health. Child Abuse Negl 2020;101:104330.

6. Slopen N, Koenen KC, Kubzansky LD. Cumulative adversity in childhood and emergent risk factors for long-term health. J Pediatr 2014;164:631-8. e1-2.

7. Committee on the Rights of the Child. General comment No. 8: The right of the child to protection from corporal punishment and other cruel or degrading forms of punishment 2006. Accessed June 6, 2015. http://www.unhchr.ch/tbs/doc.nsf/898586bldc7b4043c1256a450044f331/ 6545c032cb57bff5c12571fc002e834d/\$FILE/G0740771.pdf

8. Sege RD, Siegel BS. Council on Child Abuse and Neglect, Committee on Psychosocial Aspects of Child and Family Health. Effective discipline to raise healthy children. Pediatrics 2018;142:e20183112.

9. American Psychological Association. Resolution on physical discipline of children by parents. Washington (DC): American Psychological Association; 2019.

10. Gershoff ET, Grogan-Kaylor A. Spanking and child outcomes: Old controversies and new meta-analyses. J Fam Psychol 2016;30:453-69.

11. Afifi TO. Considerations for expanding the definition of ACEs. In: Asmundson GJG, Afifi TO, eds. Adverse childhood experiences: using evidence to advance research, practice, policy, and prevention. Cambridge (MA): Academic Press; 2019. p. 35-44.

12. Merrick MT, Ports KA, Ford DC, Afifi TO, Gershoff ET, GroganKaylor A. Unpacking the impact of adverse childhood experiences on adult mental health. Child Abuse Negl 2017;69:10-9.

13. Afifi TO, Ford D, Gershoff ET, Merrick M, Grogan-Kaylor A, Ports KA, et al. Spanking and adult mental health impairment: The case for the designation of spanking as an adverse childhood experience. Child Abuse Negl 2017;71:24-31.

14. Brown AS, Holden GW, Ashraf R. Spank, slap, or hit? How labels alter perceptions of child discipline. Psychol Violence 2018;8:1-9.

15. Ma J, Grogan-Kaylor A. Longitudinal associations of neighborhood collective efficacy and maternal corporal punishment with behavior problems in early childhood. Dev Psychol 2017;53:1027-41.

16. Taylor CA, Manganello JA, Lee SJ, Rice JC. Mothers'spanking of 3-yearold children and subsequent risk of children's aggressive behavior. Pediatrics 2010;125:e1057-65.

17. Lee SJ, Altschul I, Gershoff ET. Does warmth moderate longitudinal associations between maternal spanking and child aggression in early childhood? Dev Psychol 2013;49:2017-28.

18. Ma J, Grogan-Kaylor A, Lee SJ. Does community violence exposure moderate the associations between maternal spanking and early child behavior problems? Aggress Behav 2020;46:210-9.

19. Lee SJ, Pace GT, Ward KP, Grogan-Kaylor A, Ma J. Household economic hardship as a moderator of the associations between maternal spanking and child externalizing behavior problems. Child Abuse Negl 2020;107: 104573.

20. Gershoff ET, Grogan-Kaylor A, Lansford JE, Chang L, Zelli A, DeaterDeckard K, et al. Parent discipline practices in an international sample: 
associations with child behaviors and moderation by perceived normativeness. Child Dev 2010;81:487-502.

21. Grogan-Kaylor A, Castillo B, Ma J, Ward KP, Lee SJ, Pace GT, et al. A Bayesian analysis of associations between neighborhoods, spanking and child externalizing behavior. Child Youth Serv Rev 2020;112:104930.

22. Reichman NE, Teitler JO, Garfinkel I, McLanahan SS. Fragile Families: sample and design. Child Youth Serv Rev 2001;23:303-26.

23. White IR, Royston P, Wood AM. Multiple imputation using chained equations: issues and guidance for practice. Stat Med 2011;30:377-99.

24. Achenbach TM. Integrative guide for the 1991 CBCL/4-18, YSR, and TRF profiles. Burlington: Department of Psychiatry, University of Vermont Burlington; 1991.

25. Straus MA, Hamby SL, Finkelhor D, Moore DW, Runyan D. Identification of child maltreatment with the Parent-Child Conflict Tactics Scales: development and psychometric data for a national sample of American parents. Child Abuse Negl 1998;22:249-70.

26. Straus MA. Scoring the CTS2 and CTSPC. Durham (NH): Family Research Laboratory, University of New Hampshire; 2004.

27. Kessler RC, Andrews G, Mroczek D, Ustun B, Wittchen H-U. The World Health Organization Composite International Diagnostic Interview short-form (CIDI-SF). Int J Methods Psychiatr Res 1998;7:171-85.

28. Straus MA, Hamby SL, Boney-McCoy S, Sugarman DB. The Revised Conflict Tactics Scales (CTS2) development and preliminary psychometric data. J Fam Issues 1996;17:283-316.

29. Lloyd S. Physical aggression, distress, and everyday marital interaction. In: Chan DD, Lloyd SA, eds. Family violence from a communication perspective. Thousand Oaks (CA): Sage; 1996. p. 177-98.

30. Achenbach TM. Manual for the Child Behavior Checklist/2-3 and 1992 profile. Burlington: Department of Psychiatry, University of Vermont; 1992.

31. Sampson RJ, Raudenbush SW, Earls F. Neighborhoods and violent crime: a multilevel study of collective efficacy. Science 1997;277:918-24.

32. United States Census Bureau. How the Census Bureau Measures Poverty. U S Census Bur 2020. Accessed December 10, 2020. https://www.census. gov/topics/income-poverty/poverty/guidance/poverty-measures.html

33. Raudenbush SW, Bryk AS. Hierarchical linear models: applications and data analysis methods. 2nd ed. Thousand Oaks (CA): Sage; 2002.

34. StataCorp. Stata statistical software: release 15. College Station (TX): StataCorp LLC; 2017.

35. Mukaka M. A guide to appropriate use of correlation coefficient in medical research. Malawi Med J 2012;24:69-71.

36. Liming KW, Grube WA. Wellbeing outcomes for children exposed to multiple adverse experiences in early childhood: a systematic review. Child Adolesc Soc Work J 2018;35:317-35.

37. Bandura A. Social learning theory. Englewood Cliffs (NJ): Prentice Hall; 1977.

38. Patterson GR. Coercive family process. Eugene (OR): Castalia; 1982.

39. Smith JD, Dishion TJ, Shaw DS, Wilson MN, Winter CC, Patterson GR. Coercive family process and early-onset conduct problems from age 2 to school entry. Dev Psychopathol 2014;26:917-32.

40. Durrant JE, Stewart-Tufescu A, Afifi TO. Recognizing the child's right to protection from physical violence: an update on progress and a call to action. Child Abuse Negl 2020;110:104297.

41. Bowlby J. Attachment and loss: retrospect and prospect. Am J Orthopsychiatry 1982;52:664.
42. Maguire-Jack K, Gromoske AN, Berger LM. Spanking and child development during the first 5 years of life. Child Dev 2012;83: 1960-77.

43. Zahn-Waxler C, Klimes-Dougan B, Slattery MJ. Internalizing problems of childhood and adolescence: prospects, pitfalls, and progress in understanding the development of anxiety and depression. Dev Psychopathol 2000;12:443-66.

44. Bethell CD, Davis MB, Gombojav N, Stumbo S, Powers K. Issue brief: a national and across state profile on adverse childhood experiences among children and possibilities to heal and thrive. Baltimore: Johns Hopkins Bloomberg School of Public Health; 2017.

45. Lee SJ, Grogan-Kaylor A, Berger LM. Parental spanking of 1-year-old children and subsequent child protective services involvement. Child Abuse Negl 2014;38:875-83.

46. Ma J, Grogan-Kaylor A, Klein S. Neighborhood collective efficacy, parental spanking, and subsequent risk of household child protective services involvement. Child Abuse Negl 2018;80:90-8.

47. American Academy of Pediatrics. Teaching good behavior: tips on how to discipline 2006. Accessed December 11, 2020. https://patiented. solutions.aap.org/handout.aspx?gbosid $=166265$

48. American Academy of Pediatrics. What's the best way to discipline my child? HealthyChildren.Org 2018. Accessed December 11, 2020. https://www.healthychildren.org/English/family-life/family-dynamics/ communication-discipline/Pages/Disciplining-Your-Child.aspx

49. McLennan JD, McTavish JR, MacMillan HL. Routine screening of ACEs: should we or shouldn't we? In: Asmundson GJG, Afifi TO, eds. Adverse childhood experiences: using evidence to advance research, practice, policy, and prevention. Cambridge (MA): Academic Press; 2020. p. 145-59.

50. Dubowitz H, Feigelman S, Lane W, Kim J. Pediatric primary care to help prevent child maltreatment: the Safe Environment for Every Kid (SEEK) Model. Pediatrics 2009;123:858-64.

51. Dubowitz H, Lane WG, Semiatin JN, Magder LS. The SEEK model of pediatric primary care: can child maltreatment be prevented in a low-risk population? Acad Pediatr 2012;12:259-68.

52. Global Initiative to End All Corporal Punishment of Children. Accessed December 13, 2020. https://endcorporalpunishment.org/countdown/

53. Fortson BL, Klevens J, Merrick MT, Gilbert LK, Alexander SP. Preventing child abuse and neglect: a technical package for policy, norm, and programmatic activities. Atlanta: National Center for Injury Prevention and Control.; 2016.

54. Merrick MT, Ports KA, Guinn AS, Ford DC. Safe, stable, nurturing environments for children. In: Asmundson GJG, Afifi TO, eds. Adverse childhood experiences: using evidence to advance research, practice, policy, and prevention. Cambridge (MA): Academic Press; 2020. p. 329-47.

55. Lee SJ, Altschul I, Gershoff ET. Wait until your father gets home? Mother's and fathers' spanking and development of child aggression. Child Youth Serv Rev 2015;52:158166.

56. Ma J, Grogan-Kaylor A, Lee SJ. Associations of neighborhood disorganization and maternal spanking with children's aggression: a fixed-effects regression analysis. Child Abuse Negl 2018;76:106-16.

57. Gershoff ET, Grogan-Kaylor A. Race as a moderator of associations between spanking and child outcomes. Fam Relat 2016;65: 490-501. 